\title{
La SEA destaca la importancia de la investigación aplicada sobre arcillas en el campo de la cerámica
}

\section{Primera Circular}

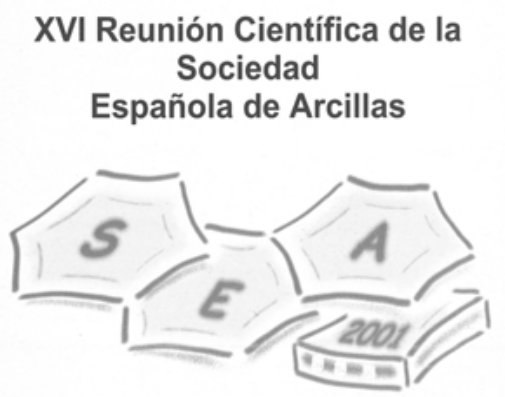

Curso sobre

Materias primas y métodos de producción de materiales cerámicos

Baeza

del 22 al 26 de octubre de 2001

\section{ORGANIZAN}

\begin{tabular}{|c|}
\hline \multicolumn{2}{|c|}{ ORGANIZAN } \\
\hline $\begin{array}{c}\text { Sociedad } \\
\text { Española de Arcillas }\end{array}$ \\
$\begin{array}{c}\text { Universidad } \\
\text { Universidad de Jaén } \\
\text { Internacional de Andalucía }\end{array}$ \\
\hline
\end{tabular}

La XVI Reunión Cientíica de la Sociedad Española de Arcillas, organizada por la Sociedad Española de Arcillas, la Universidad de Jaén, el Consejo Superior de Investigaciones Científicas y la Universidad Internacional de Andalucía se celebró en la Sede "Antonio Machado" de la Universidad Internacional de Andalucía en Baeza (Jaén) entre el 24 y el 26 de octubre de 2001 . Juan Jiménez Millán y María José de la Torre López (Departamento de Geología, Universidad de Jaén) coordinaron la reunión. El espectro de conocimientos tratados en esta reunión ha incluido desde de los estudios metodológicos y de carácter básico, relacionados con la estructura y génesis de las arcillas, hasta las aplicaciones prácticas derivadas de la investigación del comportamiento de estos materiales. En esta ocasión, el eje principal de la reunión científica pretende promocionar y difundir la importancia de las investigaciones aplicadas sobre arcillas, especialmente, en el campo de la cerámica.

Por este motivo, en el marco de esta reunión se celebró el curso de la Universidad Internacional de Andalucía "Materias primas y métodos de producción de materiales cerámicos". Juan Jiménez Millán y María José de la Torre López intervinieron como directores de este curso, en el que se ha reunido a un amplio número de especialistas de reconocido prestigio en el ámbito de la cerámica para exponer sus experiencias en el uso de la metodología de trabajo en la evaluación de las posibilidades de uso cerámico de las materias primas arcillosas, la innovación relacionada con la obtención de nuevos materiales cerámicos obtenidos a partir de la experimentación con arcillas, los avances tecnológicos del proceso de fabricación, los problemas de impacto ambiental asociados a la explotación de las materias primas y a la elaboración de los productos cerámicos y la información proporcionada por el estudio de las cerámicas antiguas.

Dada la importancia del uso de las arcillas en la elaboración de cerámicas a lo largo de las civilizaciones, tanto en la XVI Reunión Científica de la Sociedad Española de Arcillas como en el Curso de Materias Primas y Métodos de Producción de Materiales Cerámicos se desarrollaron sesiones específicamente dedicadas a la Cerámica antigua, la arqueometría y el patrimonio.

La Sesión de cerámica antigua y patrimonio de la XVI Reunión Científica de la Sociedad Española de Arcillas estuvo presidida por el Profesor Celso Gomes (Universidad de Aveiro) contó con las siguientes comunicaciones:

- Conferencia introductoria.

Estudios arqueométricos. María José de la Torre López. Universidad de Jaén.

- Trasformaciones mineralógicas en ladrillos macizos con aditivos. Cultrone, G.; Sebastián, E.; de la Torre, M.j; Rodríguez Navarro, C.; Cazalla, O.

- Estudio de la procedencia de fragmentos de piezas cerámicas arqueológicas y otras tomadas "in situ" de Salobreña (Granada). García Ramos, G.; de Andrés, A.M.; Muñoz Pascual, l.; Vargas Muñoz, M.
- Análisis comparativo de azulejos originales y de reposición en el Paseo de Catalina de Ribera y Jardines de Murillo (Sevilla). Flores, V.; Aparicio, P.; Alejandre, J.

- In situ development of clay minerals in natural ornamental stone as is the case of the volcanic tuff facing the funchal cathedral, Madeira archipelago. Silva, J.; Naudin, J.M.; Gomes, C.

- Estudio de cerámicas procedentes del estanque del jardín de las flores del Real Alcázar de Sevilla. Sigüenza Caballo, M.B.; Justo Érbez, A.; Jiménez de Haro, M.C.; jiménez Roca, E.; Martínez Blanes, J.M.; Robador González, D.; Pérez Rodríguez, J.L.

Estos trabajos pueden encontrarse en el libro editado por la Sociedad Española de Arcillas Nuevas Tendencias en el Estudio de las Arcillas (Jiménez Millán J, ed).

El apartado de cerámica antigua y arqueometría del Curso de Materias Primas y Métodos de Producción de Materiales Cerámicos contó con las siguientes ponencias:

- Le metodologie mineralogico-petrografiche e chimiche nello studio delle ceramiche antiche. Roberto Falcone. Stazione Sperimentale del Vetro. Murano. Venezia.

- Análisis arqueométrico de los vidriados cerámicos. Judit Molera. Dept. Cristalografia, Mineralogia i Dipòsits Minerals. Universitat de Barcelona.

El contenido de estas ponencias puede consultarse en el libro editado por la Sociedad Española de Arcillas Materias Primas y Métodos de Producción de Materiales Cerámicos (Jiménez Millán J, ed.).

Juan Jiménez Millán María José de la Torre López

Coordinadores de la Reunión Departamento de Geología Universidad de Jaén 